LBNL-55305

\title{
Estimating energy-augmenting technological change in developing country industries
}

\author{
Alan H. Sanstad, and Jayant A. Sathaye, ${ }^{\text {, }}$ \\ Lawrence Berkeley National Laboratory \\ Joyashree Roy \\ Jadavpur University \\ September 2006
}

\begin{abstract}
Assumptions regarding the magnitude and direction of energy-related technological change have long been recognized as critical determinants of the outputs and policy conclusions derived from integrated assessment models. Particularly in the case of developing countries, however, empirical analysis of technological change has lagged behind simulation modeling. This paper presents estimates of sectoral productivity trends and energy-augmenting technological change for several energy-intensive industries in India and South Korea, and, for comparison, the United States. The key findings are substantial heterogeneity among both industries and countries, and a number of cases of declining energy efficiency. The results are subject to certain technical qualifications both in regards to the methodology and to the direct comparison to integrated assessment parameterizations. Nevertheless, they highlight the importance of closer attention to the empirical basis for common modeling assumptions.
\end{abstract}

Keywords: Technological change; Developing countries; Industry

\section{Introduction}

Integrated assessment (IA) models applied to long-range energy or climate policy analysis are now generally structured to represent energy and economic trends on a global scale. While appropriate for the problems to which it is applied, this modeling approach is nevertheless subject to certain empirical limitations. First, the relative scarcity of suitable statistical information on many developing economies in comparison to that available for the U.S. and other mature economies often compels modelers to apply parameters estimated for the latter to the former. Second, recent econometric estimates of parameters governing technological change are relatively scarce even for industrialized countries, so that these parameters are often set in IA models according to calibration requirements, indirect evidence and judgement. Given both the need for global-scale policy analysis and the well-known importance of technological change in determining modeled outcomes of policies to influence energy demand or greenhouse gas 
emissions, these considerations indicate the value of further empirical investigation of technological change relating to energy in developing country economies.

This paper presents results from such an investigation, focusing on India and South Korea. The departure point for this effort is the work of Hogan and Jorgenson (1991), who analyzed the socalled rate of "autonomous energy-efficiency improvement" or "AEEI" (a term apparently coined by Manne and Richels, 1990 and Manne and Richels, 1992) in the U.S. economy. In its original usage, this terminology referred to aggregate declines in energy intensity - that is, declines in the energy-to-gross domestic product ratio $\frac{E}{\mathrm{GDP}}-$ arising from influences other than price-induced substitution away from energy in the production of economic output. At this level, such declines can arise not only from energy-saving technological change but also from structural change or sectoral shifts in the composition of output favoring less energy-intensive industries, among other factors. The "AEEI" terminology has also, however, come to mean autonomous (i.e., non-price-induced) energy-efficiency trends at the sectoral or industry level (see, e.g., Babiker et al., 2001). At this level, under standard assumptions - including cost minimization on the part of entire industries - such general equilibrium or macroeconomic influences contribute only indirectly to the rate of AEEI, which is thus a more direct measure of technological change. In this paper, we focus on this industry level, and estimate, for each of several Indian and South Korean industries, an "autonomous trend" appropriate to this level of analysis. The estimations employ an underlying translog cost model and data drawn from Indian and South Korean sources. For comparison, we also present parallel estimations on several U.S. industries.

The use of the translog model for this purpose is purely pragmatic. Most current integrated assessment models eschew flexible functional forms such as the translog in favor of such forms as the constant elasticity-of-substitution (CES) or Leontief, often in combination and with separability (nesting) imposed. Parameters governing the AEEI and other efficiency trends (such as changes in labor productivity) are then embedded in these production structures. The nested CES in particular, however, is difficult to estimate; indeed, there appears to be no published econometric estimation of a nested CES model with general factor-augmenting technical change, even in a degree of complexity less than that common in IA and energy simulation models. . $^{3}$ Instead, econometric analysis of technical change related to energy has been carried out for the most part (although not exclusively) using translog and other flexible functional forms.

The work described here adopts this approach as well, but rather than focusing on the familiar dual efficiency index of "factor price bias" we instead calculate autonomous energy trends in terms of energy intensity (energy per unit output), which better corresponds to the use of the AEEI idea in energy and IA modeling. This calculation entails a loss-of-generality resulting from the maintained assumption of constant factor price bias in our underlying model. In addition, there are a number of other technical issues qualifying the direct comparison or application of these results to parameterizations in IA models. Nevertheless, we interpret these results as providing one set of quantitative benchmarks against which simulation model characteristics can be compared, in effect, qualitatively. The general goal is to contribute to the body of theory and evidence available for evaluating and enhancing the performance of IA models. 


\section{Theoretical background}

A close reading of the literature on the AEEI reveals a certain ambiguity between the underlying concept and the manner in which it is represented or indexed in particular models using specific functional forms. For this reason, it is useful to have an "intrinsic" definition in terms of underlying theory. We begin by providing one, following Hogan and Jorgenson (op cit.).

Consider a production function $Y_{t}=f\left(\vec{x}_{t} t\right)$, where $\overrightarrow{x_{t}}$ is a vector of inputs and as usual the inclusion of time $t$ as an argument means that the production relationship is assumed to change over time. (Below, we will be somewhat casual about including time subscripts, but the meaning of the notation should be clear in context.) We interpret this function as describing production at a sectoral or industry level (with cost minimization as the implicit decision rule), and make the additional standard assumptions that output $Y_{t}$ is exogenous and that $f(\cdot$,$) is differentiable and$ embodies constant-returns-to-scale, so that the dual cost function $C\left(\overrightarrow{p_{t}}, t\right)$ exists and can be written as

$$
C\left(\overrightarrow{p_{n}}, t\right)=Y_{\rho} \rho\left(\overrightarrow{p_{t}}, t\right)
$$

where $\overrightarrow{p_{t}}$ is a vector of prices and $c\left(\vec{p}_{t} t\right)$ is the unit cost function. In this setting, the natural definition of the "autonomous efficiency trend" for the $i$ th factor is

$$
\varepsilon_{i f}=-\frac{\partial \ln \left(\frac{x}{r}\right)}{\partial t}
$$

(cf. Hogan and Jorgenson, op cit.; see also Chambers, 1988). We can derive an expression for this trend that is closer to practical application as follows. By Shephard's Lemma, i.e.,

$$
x_{\xi}=\frac{\partial C}{\partial p_{i}}
$$

we can write

$$
x_{i}=\gamma \frac{C_{e}}{\partial p_{i}}
$$

which implies

$$
\frac{x_{i}}{\underline{y}}=\frac{\partial \varepsilon}{\partial p_{i}}
$$

and in turn

$$
\tau_{i t}=-\frac{\partial}{\partial t} \ln \left(\frac{\partial c}{\partial p_{i}}\right)
$$


Some intuition for this result can be obtained by relating it to two more familiar measures of technical change, the $i$ th factor price bias $\theta_{i}$ and the rate of sectoral productivity change $v_{t}$. (See, for example, Jorgenson et al., 1987.) These are defined as

$$
\theta_{i f}=\frac{\partial s_{i f}}{\partial t}
$$

where

$$
s_{i t}=\frac{p_{i d i}}{p_{\text {Aq }} Y_{i}}
$$

is the $i^{\text {th }}$ cost share ( $p_{q}$ is the price of output), and

$$
v_{t}=-\frac{\hat{\partial} \ln \omega(p, t)}{\partial t}
$$

It can be shown (Hogan and Jorgenson, Eq. (11)) that

$$
-\tau_{i t}=\frac{\theta_{i t}}{s_{i t}}-v_{i}
$$

so that, re-arranging,

$$
\theta_{i t}=s_{i t}\left(\mathrm{v}_{t}-\tau_{i t}\right)
$$

or in words, the factor price bias is the share-weighted deviation of the autonomous efficiency trend from the sectoral productivity trend.

The most familiar instance of the factor price bias is in translog models in which (as in the following section) the bias is constant. Eq. (11) is a reminder that, in terms of general theory, constancy is neither implied nor required (and as we discuss below, does imply a loss of generality in our application). The equation also demonstrates that the relation between the factor price bias and the autonomous trend is mediated by the sectoral productivity trend (and that, empirically, all three are jointly determined). As an aside, recalling that factor price bias measures the time trend of the corresponding cost share independent of the influence of price changes, it is natural to assume that the bias and the autonomous efficiency trend would have opposite signs. This would mean that the cost share declines due to technological change (negative bias) if and only if the efficiency trend is positive, that is, the share of the factor in total output declines due to technological change. As the equation shows, however, this is not dictated by underlying theory, and in our empirical results does not hold in every case.

\section{Application to the translog cost function}

To apply the above results empirically, we employ a translog cost model of the form 


$$
\ln (c)=\ln a_{0}+\sum_{i} a_{k} \ln p_{k}+a_{t} \xi+\frac{1}{2} \sum_{\hbar} \sum_{i} b_{k i} \ln p_{k} \ln p_{i}+\sum_{\zeta} b_{\delta i} \ln p_{k} t+\frac{1}{2} b_{t h} t^{2}
$$

where the parameter $b_{k t}$ is the factor price bias for the $k^{\text {th }}$ input and is assumed constant over time. It is straightforward to show that for this model

$$
\begin{aligned}
& s_{i t}=a_{i}+\sum_{i}^{n_{i}} b_{i k} \operatorname{In} p_{k}+b_{i k t} \\
& -b_{t}=a_{t}+\sum_{k} b_{b k} \ln p_{t}+b_{l k} t
\end{aligned}
$$

and

$$
\tau_{i t}=v_{r}=\frac{b_{i x}}{s_{i e}}
$$

This last relationship reflects Eqs. (10) and (11) above, with the difference noted previously that the bias is constant. Note that this model embodies constant-returns-to-scale. It also reflects the assumption that cost minimization is a reasonable behavioral description of the modeled industries; the validity of this assumption in this context is discussed in Roy et al. (1999). We also note that universal cost minimization is the standard assumption in IA modeling.

A translog cost model of this form with input factors $K, L, E$ and $M$ (capital, labor, energy and materials) was estimated on Indian, South Korean and U.S. industry data. In all cases, all factors (notably including capital) were assumed variable. As is standard, one equation (in this case, for materials) was dropped to avoid singularity and the remaining three jointly estimated along with the cost function, with symmetry and homogeneity restrictions imposed on the parameters. Estimates were obtained via the iterative Zellner-efficient estimator; no correction for autocorrelation was made.

Local concavity (that is, concavity at each observation in the various data series) was imposed using the method of Ryan and Wales (2000). We note that the imposition of concavity restrictions appears to be something of an exception in the literature, and that a common practice is to instead report the number of observations at which the estimated cost or production function fails these restrictions. While instructive, this leaves the problem that, at these observations, the estimated model in fact fails to be a cost or production function, which complicates interpretation and applications to policy analysis. As demonstrated by Berndt and Wood (1982), imposing global concavity on translog estimates, as in Jorgenson and Fraumeni (1981), results in a substantial loss of generality. On the other hand, Perroni and Rutherford (1998) show that the satisfaction of the local restrictions only can limit the size of the out-of-sample domain in which the concavity restriction remains valid, at least relative to alternative functional forms. All-in-all, this problem appears to reflect an unavoidable trade-off in applying the translog form, and we adopt the local restrictions as a reasonable compromise. 
The data (on prices and cost shares) spanned the interval 1973-1994 for six energy-intensive Indian industries - aluminum, cement, fertilizer, glass, pulp and paper, and iron and steel - as well as Indian aggregate manufacturing, and the interval 1980-1997 for four energy-intensive South Korean industries - cement, fertilizer, pulp and paper, and iron and steel - as well as South Korean aggregate manufacturing; these data were obtained from Indian and South Korean government sources (Government of India 1, (various years), Government of India 2, (various years), Bank of Korea 1, (various years) and Bank of Korea 2, (various years)). Data for three U.S. energy-intensive industries - paper and allied products, chemicals and primary metals were those created (and made publicly available) by Dale Jorgenson and his colleagues, and spanned the interval 1958-1996. ${ }^{4}$ Although these U.S. industries are not precisely equivalent to the Indian or South Korean, they do provide for a general comparison between the features (as viewed through the lens of our particular model) of energy-intensive industries in the U.S. and the other two countries.

\section{Results}

Our results are summarized in Table 1 , Table 2 and Table 3 . Before discussing the results specifically, an explanation is in order regarding the selection of the particular numbers we report from the larger set generated by the analysis. $\frac{5}{}$

The definitions of both sectoral productivity and the autonomous energy-efficiency trend imply that, while they are independent of changes in prices - that is, time derivatives of prices - they are implicitly functions of price levels among other inputs. Thus, measured on a year-to-year basis, they will reveal fluctuations due to price fluctuations. The common approach is therefore to calculate such technological change trends in terms of prices fixed at some "base" year. We follow this convention, but it is important to note that in our results there is an additional source of variation in the autonomous energy-efficiency trend due to the constant energy price bias assumption. This can be seen from Eq. (11): Assume, for the sake of discussion, a constant rate of sectoral productivity change. Then the constancy of the bias results in fluctuations in the cost share in turn generating fluctuations in the autonomous energy-efficiency trend (in order for the equation to hold). (This can also be inferred from Eq. (15).) Fluctuations in the sectoral productivity trend due to price changes obscure, but do not change, this effect. 
Table 1. Technological change summary statistics_-Indian industries, 1973-1994

\begin{tabular}{|l|l|l|l|l|l|}
\hline & $\begin{array}{l}\text { Energy price } \\
\text { bias (standard } \\
\text { error) }\end{array}$ & \multicolumn{2}{l|}{$\begin{array}{l}\text { Time averages (in percent) of sectoral productivity and autonomous } \\
\text { energy efficiency trend }\end{array}$} \\
\hline Industry & & $\begin{array}{l}\text { Prices and energy cost share } \\
\text { fixed at base year }\end{array}$ & \multicolumn{2}{l|}{$\begin{array}{l}\text { Prices and energy cost share fixed } \\
\text { at mid-point year }\end{array}$} \\
\cline { 3 - 4 } & & Productivity & $\begin{array}{l}\text { Autonomous } \\
\text { trend }\end{array}$ & Productivity & $\begin{array}{l}\text { Autonomous } \\
\text { trend }\end{array}$ \\
\hline $\begin{array}{l}\text { Aggregate } \\
\text { manufacturing }\end{array}$ & $0.00064(0.0002)$ & $0.21 \%$ & $-1.18 \%$ & $-1.17 \%$ & $-1.96 \%$ \\
\hline Aluminum & $0.00966(0.002)$ & $-0.71 \%$ & $-7.9 \%$ & $-1.12 \%$ & $-4.3 \%$ \\
\hline Cement & $0.00749(0.0004)$ & $0.98 \%$ & $-2.44 \%$ & $1.47 \%$ & $-1.18 \%$ \\
\hline Fertilizer & $0.0068(0.001)$ & $2.84 \%$ & $-4.27 \%$ & $0.94 \%$ & $-2.89 \%$ \\
\hline Glass & $0.00192(0.0007)$ & $2.13 \%$ & $1.09 \%$ & $2.79 \%$ & $2.15 \%$ \\
\hline Iron and steel & $\begin{array}{l}-0.00196 \\
(0.0006)\end{array}$ & $-1.49 \%$ & $0.36 \%$ & $-1.13 \%$ & $0.1 \%$ \\
\hline Pulp and paper & $0.00328(0.0004)$ & $-0.23 \%$ & $-3.38 \%$ & $-0.81 \%$ & $-2.70 \%$ \\
\hline & & & & & \\
\hline
\end{tabular}

In the dual model we apply here, constant factor price biases influencing price-independent time trends in cost shares exactly reflect the assumption of constant rates of factor-augmenting technical change - price-independent time trends in input shares - in the primal or production function context. The problem of share-driven variation in the autonomous energy-efficiency trend is essentially an artifact of our applying this dual model to the estimation of the primal energy intensity, and constitutes a caveat for the interpretation of our results. Nevertheless, we believe that these results are instructive with regard to the general pattern of the energy trend across countries and industries. 
Table 2. Technological change summary statistics-South Korean industries, 1980-1997

\begin{tabular}{|l|l|l|l|l|l|}
\hline & $\begin{array}{l}\text { Energy price } \\
\text { bias (standard } \\
\text { error) }\end{array}$ & $\begin{array}{l}\text { Time averages (in percent) of sectoral productivity and autonomous } \\
\text { energy efficiency trend }\end{array}$ \\
& & $\begin{array}{l}\text { Prices and energy cost share } \\
\text { fixed at base year }\end{array}$ & \multicolumn{2}{l|}{$\begin{array}{l}\text { Prices and energy cost share fixed } \\
\text { at mid-point year }\end{array}$} \\
\hline Industry & Productivity & $\begin{array}{l}\text { Autonomous } \\
\text { trend }\end{array}$ & Productivity & $\begin{array}{l}\text { Autonomous } \\
\text { trend }\end{array}$ \\
\hline $\begin{array}{l}\text { Aggregate } \\
\text { manufacturing }\end{array}$ & $\begin{array}{l}-0.00197 \\
(0.0003)\end{array}$ & $1.13 \%$ & $4.3 \%$ & $1.54 \%$ & $7.5 \%$ \\
\hline Cement & $0.00347(0.0018)$ & $0.9 \%$ & $-0.196 \%$ & $1.27 \%$ & $-0.24 \%$ \\
\hline Fertilizer & $\begin{array}{l}-0.00458 \\
(0.0014)\end{array}$ & $-0.71 \%$ & $3.09 \%$ & $-0.34 \%$ & $5.08 \%$ \\
\hline Iron and steel & $-0.0005(0.0034)$ & $0.82 \%$ & $1.52 \%$ & $0.71 \%$ & $1.55 \%$ \\
\hline Pulp and paper & $0.00159(0.0008)$ & $0.55 \%$ & $-0.73 \%$ & $0.49 \%$ & $-1.99 \%$ \\
\hline
\end{tabular}

Table 3. Technological change summary statistics-U.S. industries, 19581996

\begin{tabular}{|l|l|l|l|l|l|}
\hline & \multicolumn{2}{|l|}{$\begin{array}{l}\text { Energy price bias } \\
\text { (standard error) }\end{array}$} & $\begin{array}{l}\text { Time averages of sectoral productivity and autonomous energy } \\
\text { efficiency trend }\end{array}$ \\
\hline & & $\begin{array}{l}\text { Prices and energy cost share fixed } \\
\text { at base year }\end{array}$ & $\begin{array}{l}\text { Prices and energy cost share fixed } \\
\text { at mid-point year }\end{array}$ \\
\hline Industry & & Productivity & $\begin{array}{l}\text { Autonomous } \\
\text { trend }\end{array}$ & Productivity & $\begin{array}{l}\text { Autonomous } \\
\text { trend }\end{array}$ \\
\hline Chemicals & $0.00056(0.0001)$ & $0.66 \%$ & $-1.57 \%$ & $0.68 \%$ & $-0.21 \%$ \\
\hline $\begin{array}{l}\text { Paper and } \\
\text { allied products }\end{array}$ & $0.00062(0.0001)$ & $0.46 \%$ & $-1.72 \%$ & $0.40 \%$ & $-0.91 \%$ \\
\hline Primary metals & $0.00141(0.0002)$ & $0.22 \%$ & $-2.67 \%$ & $0.67 \%$ & $-1.13 \%$ \\
\hline
\end{tabular}

In light of these considerations, we compute the sectoral productivity trend and the energyefficiency trend (for each industry and country) in two ways, as follows. First, prices and the energy cost share are fixed at the first year in each sample, the productivity and energy trends are calculated for each subsequent year, and the simple average of each over time is calculated. Second, prices and the energy cost share are fixed at the mid-point year of each sample, then the 
two measures calculated for each year in the remaining period of the sample, and the time averages again calculated. The results, along with the energy price bias estimates, are presented in the tables.

This approach allows us both to gauge the effect of the choice of base year on the estimates of the two trends and to a certain extent determine the robustness of the energy-efficiency trend estimates to the share-variation problem. In this regard, as shown in the tables, with one exception - Indian aggregate manufacturing - neither the productivity trend nor the energyefficiency trend changes sign between the two calculations, so that with this exception the identification of overall technical as well as energy-specific "progress" or "regress" is robust to both changes in factor prices and variation in the energy cost share.

A second observation concerns the relation among the factor price bias, the productivity trend and the autonomous energy trend. Eq. (15) shows that the productivity trend is an upper or lower bound for the energy trend depending on the sign of the bias. Thus, for example, a negative productivity trend and a positive bias ensure a negative energy-efficiency trend; examples are Indian aluminum and pulp and paper. On the other hand, even with a positive productivity trend, the energy-efficiency trend can be negative depending on the magnitude of the former and providing the bias is positive and of sufficient magnitude; examples here are Indian cement and fertilizer, South Korean cement and pulp and paper, and all three of the U.S. industries. A negative productivity trend can coincide with a positive energy-efficiency trend if the bias is negative, as occurs in Indian iron and steel and South Korean fertilizer. Finally, positive productivity and energy-efficiency trends can co-occur through a negative bias, with the examples here being South Korean aggregate manufacturing and iron and steel. In regard to the remarks immediately following Eq. (11), above, we note that the dual measure of energyefficiency change - the price bias - and our indirect primal measure - the autonomous trend coincide in all cases but one, Indian glass.

With these observations in hand, we turn to three patterns in the results that are in principle of interest in regard to comparisons with IA models. First, regardless of the sign, the magnitudes of a number of the estimates would appear to be substantially greater than would be expected on the basis of conventional wisdom. To some extent, these large magnitudes may be a function of our use of a linear rather than, for example, a logit-based time trend, although we would not necessarily expect an alternative representation of the time trend to alter the signs of the productivity or energy-efficiency trends. This is a topic for further research.

Second, there is substantial heterogeneity among industries, including industries within a given country. In the Indian results, for example, the glass industry displays positive rates of both productivity and energy-efficiency change, while the pulp and paper industry displays negative rates of both, and in the cement industry sectoral productivity improves while energy efficiency declines. Similarly, in the South Korean results, we see positive rates of both measures (aggregate manufacturing, iron and steel), productivity improvements and energy-efficiency declines (cement, pulp and paper), and productivity declines but energy-efficiency improvements (fertilizer). Even in the U.S. results, in which the pattern of signs is the same among the three industries, there is a reasonably large spread among the autonomous energy-efficiency trend estimates. 
Third, there is across these results clearly no generic pattern of improvements in energy efficiency. The "best" results are for South Korea, in which three out of five industries display a positive energy-efficiency trend in both the first-year and the mid-year-based estimates. However, in India, the energy trend is negative in five of the seven industries and is negative in each of the three U.S. industries. The U.S. results, at least, echo the previous conclusion of Jorgenson and his collaborators in a number of studies, i.e., that technological change (in the U.S.) is in many cases "energy-using" rather than "energy-saving" (or, is characterized by a positive rather than negative factor price bias). The findings here indicate that this phenomenon also appears in other countries.

In addition to the issue discussed above (variation in the autonomous energy trend resulting from variation in the energy cost share), there are a number of other qualifications that must be mentioned given that the purpose of this analysis is to inform, even in general terms, IA modeling practice. First, this is of course a retrospective study, while IA models are in practice used exclusively for forecasting or scenario projections. Second, even under the basic theoretical assumptions - cost minimization, constant-returns-to-scale, etc. - that may be common across the application of different functional forms, the translog model has different statistical characteristics than forms such as the CES that are generally used in IA models, so that one cannot predict with complete confidence that conducting this analysis with such forms (were that feasible) would yield closely analogous results. Third, although separability could in principle be imposed on this translog model, its absence here creates another difference from the nested structures that are common in IA models. Fourth, in addition to its influence on the present analysis, the particular feature of constant factor price biases further distinguishes this translog model from nested CES and/or Leontieff models with factor-augmenting technical change. Fifth, most if not all IA models embody much more detail on energy supply and demand than the model we apply here, for example in the disaggregation of energy inputs into different fuels. The implication of these points is that, even were it possible to econometrically estimate directly the functional forms used in specific IA models (which, in general, it is not), the results could be expected to differ from those obtained here. ${ }^{6}$ Finally, it is important to note that the assumption of variable capital and the absence of any vintaging in this model means that (subject to the caveats just listed) the general correspondence that is appropriate to draw is to the "putty" part of "putty-clay" models, rather than to the full representations of industries in IA models, which typically include such features as adjustment costs, vintaging and/or short-term capital fixity.

Even with these qualifications, however, we can compare the results here in general terms to parameterizations that appear standard in IA modeling. With regard to the retrospective vs. prospective distinction, while very long-term projections might be considered in principle unconstrained by historical patterns, it is also arguable that the recent past is a not-unreasonable guide for nearer-term projections - say, on the order of two to three decades. (In addition, of course, in long-run model-generated scenarios, the first several decades essentially provide initial and/or boundary conditions for time intervals further in the future.) Second, modelers generally assume that productivity in general (total factor as well as labor) and energy productivity in particular improve across regions or countries and industries. The results here indicate that, historically, this has not necessarily been the case. Third, modelers also tend to assume identical rates of various forms of productivity improvement across countries or regions or, if there is 
regional variation, across industries within countries or regions. Here again, our results suggest that intra-country heterogeneity may be more likely the norm.

\section{Concluding remarks}

The representation of energy-related technological change in energy and, more recently, IA models - including the question of the AEEI - has been a topic of technical interest as well as policy relevance for several decades. It is somewhat surprising, therefore, that the body of empirical research that might directly inform the parameterization of these models remains rather circumscribed, particularly given the importance of technological change assumptions for modelgenerated policy recommendations. This quandary is arguably becoming even more acute with the recent emergence of "induced" and/or "endogenous" technological change as an active topic of research among energy and IA modelers. The work discussed in this paper represents one attempt to enlarge the empirical basis for discussion of IA modeling of technological change. Even with the caveats we have noted, we view our results as providing grounds for concluding that, even on the "classical" terrain of autonomous technological change, there is ample room as well as justification for further research.

\section{Acknowledgement}

We thank John Houghton of the Office of Biological and Environmental Research, U.S. Department of Energy, for supporting this research, Peter Wilcoxen and Mun Sing Ho for their advice, and Katja Schumacher for her contributions to this research effort. Work at Lawrence Berkeley National Laboratory was supported under U.S. Department of Energy Contract No. DE-AC03-SF00098.

\section{References}

Babiker et al., 2001 Mustafa H. Babiker, John M. Reilly, Monika Mayer, Richard S. Eckhaus, Ian Sue Wing and Robert C. Hyman, The MIT Emissions Prediction and Policy Analysis (EPPA) model: revisions, sensitivities, and comparisons of results, Report No. 71, MIT Joint Program on the Science and Policy of Global Change, Massachusetts Institute of Technology (2001) February.

Bank of Korea 1, (various years) Bank of Korea 1 (various years): Economic Statistics Yearbook 1979, 1990, 1996. The Bank of Korea.

Bank of Korea 2, (various years) Bank of Korea 2 (various years): Producer Prices Survey, 1973-94. Monthly Publication of The Bank of Korea.

Berndt and Wood, 1982 Ernst R. Berndt and David O. Wood, The specification and measurement of technical change in U.S. manufacturing. In: John R. Moroney, Editor, Advances in the Economics of Energy and Resources, JAI Press, Inc., Greenwich, Connecticut (1982). 
Chambers, 1988 Robert G. Chambers, Applied Production Analysis: A Dual Approach, Cambridge University Press, Cambridge, England (1988).

Dawkins et al., 2001 Christina Dawkins, T.N. Srinivasan and John Whalley, Calibration. In: James J. Heckman and Edward Leamer, Editors, Chapter 58 in Handbook of Econometrics vol. 5, North-Holland, Amsterdam (2001).

Government of India 1, (various years) Government of India 1 (various years). Annual Survey of Industries: Summary Results for Factory Sector, 1973-1993. New Delhi (India): Central Statistical Organisation, Department of Statistics, Ministry of Planning and Programme Implementation.

Government of India 2, (various years) Government of India 2 (various years). Index Numbers of Wholesale Prices in India, 1973-1993. New Delhi (India): Office of the Economic Advisor, Ministry of Finance.

Hogan and Jorgenson, 1991 William W. Hogan and Dale W. Jorgenson, Productivity trends and the cost of reducing $\mathrm{CO}_{2}$ emissions, Energy Journal 12 (1991) (1), pp. 67-85 January.

Jorgenson and Fraumeni, 1981 D.W. Jorgenson and Barbara M. Fraumeni, Relative prices and technical change. In: E.R. Berndt and B. Fields, Editors, Modeling and Measuring Natural Resources Substitution, MIT Press, Cambridge (1981).

Jorgenson et al., 1987 Dale W. Jorgenson, Frank M. Gollop and Barbara M. Fraumeni, Productivity and U.S. Economic Growth, Harvard University Press, Cambridge, Massachusetts (1987).

Kemfert, 1998 Claudia Kemfert, Estimated substitution elasticities of a nested CES production function approach for Germany, Energy Economics 20 (1998), pp. 249-264.

Manne and Richels, 1990 Alan S. Manne and Richard G. Richels, $\mathrm{CO}_{2}$ emission limits: an economic cost analysis for the USA, Energy Journal 11 (1990) (2), pp. 51-74 April.

Manne and Richels, 1992 Alan S. Manne and Richard G. Richels, Buying Greenhouse Insurance: The Economic Costs of $\mathrm{CO}_{2}$ Emissions Limits, The MIT Press, Cambridge, Massachusetts (1992).

Perroni and Rutherford, 1998 Carlo Perroni and Thomas F. Rutherford, A comparison of the performance of flexible functional forms for use in applied general equilibrium modelling, Computational Economics 11 (1998) (3), pp. 245-263 June.

Prywes, 1986 Menahem Prywes, A nested CES approach to capital-energy substitution, Energy Economics 8 (1986) (1), pp. 22-28 January. 


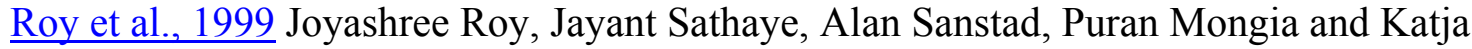
Schumacher, Productivity trends in India's energy-intensive industries, Energy Journal 20 (1999) (3) April.

Ryan and Wales, 2000 David L. Ryan and Terence J. Wales, Imposing local concavity in the translog and generalized Leontief cost functions, Economics Letters 67 (2000), pp. 253-260.

\section{Notes}

Corresponding author. Tel.: +1 510486 6433; fax: +1 5104866996.

${ }^{1}$ Tel.: +91334257382.

${ }^{2}$ Tel.: +1 510486 6294; fax: +1 5104866996 .

$\stackrel{3}{-}$ For example, Prywes (1986) estimated a nested CES model for a number of U.S. industries, but used data for a short time period (1971-1976) and included technical change only at the subaggregate rather than the factor level. Kemfert (1998) estimated several nested CES models for various German industries over longer intervals (1970 to 1988 or 1960 to 1993) but included only neutral technical change.

${ }^{4}$ These data are at http://post.economics.harvard.edu/faculty/jorgenson/data/35klem.html.

5 Further details on the results are available from the first author.

${ }^{6}$ A pertinent discussion is provided by Dawkins et al. (2001).

Published in:

Energy Economics Volume 28, Issues 5-6, November 2006, Pages 720-729. Modeling Technological Change in Climate Policy Analyses 